\title{
Information Technology and the Experience of Disorder
}

\author{
JONATHAN PAUL MARSHALL
}

UNIVERSITY OF TECHNOLOGY, SYDNEY

\section{-TECHNOLOGY AND MANAGEMENT AS MODES OF ORDERING}

Information and communication technologies (ICT) and management are critical components of contemporary social and cultural life, especially in the so-called 'information society'. Management often works through and deploys ICT, and the two are nearly always seen as ordering or controlling processes that (eventually) produce order whether efficient, liberatory or oppressive. As we shall see, governments, businesses and other organisations generally argue that a new, improved computer system will solve their problems of efficiency, order and survival. 'Order' is, in itself, usually taken as non-problematic or ultimately as beneficial-even anarchists claim they are in favour of naturally arising orders. ${ }^{1}$

However, what if ordering systems tend to be self-undermining, producing what those imposing them classify as disorder and inducing common responses of ignoring disorder, or strengthening or reimposing the ordering system, so that the cycle starts again? I am not here, suggesting that 'order' or 'disorder' are absolutes: they are socially defined and different people may not agree on what is ordered correctly, or how to order correctly, so that conflict over what constitutes order and ordering is an ongoing part of politics. I am, however, suggesting that 'order' and 'disorder' are not separable; they arise together as an order/disorder complex. 
I am here following Berg and Timmermans who, in discussing medical practice, point out that ICT is tied up with modes of ordering and standardisation.

Attempts to formalize, standardize, and rationalize are ubiquitous in Western worlds ... The disorder of current practices, according to such discourses, should be replaced by scientifically established, rational, and universal modes of working and understanding. ${ }^{2}$

The question arises whether this triumph of order is possible. Berg and Timmermans suggest that order and disorder are mutually implicated: 'these orders do not emerge out of (and thereby replace) a preexisting disorder. Rather, with the production of an order, a corresponding disorder comes into being.'3 Modes of ordering can produce 'the very disorders they attempt to eradicate. They identify the enemy that they seek to conquer-yet this identification process is not a selection of a pregiven problem, but a process wherein the specific problem is produced'; 'not only does the one come into being only with the other-it also cannot survive without it.'4 Order in one place can create disorder elsewhere.

Through examining a series of interviews, this article explores the social relationship between ordering and disordering by looking at management as a mode of ordering and describing the experience of disorder that is common in software installations, upgrades and improvements. The result shows that disorder, the failure of communication and the failure of models of 'reality' are at the heart of the information society and its ordering, despite claims by Manuel Castells that information society and ICT:

allow for co-ordination and management of complexity, in an interactive system which features feedback effects, and communication patterns from anywhere to everywhere within the networks. It follows an unprecedented combination of flexibility and task implementation, of coordinated decision making, and decentralized execution, which provide a superior social morphology for all human action. ${ }^{5}$

ICT is a good subject for opening the order/disorder complex, as it orders people by:

a. structuring communication and interaction; allocating tasks, roles and responsibilities in a division of labour

b. hierarchising those tasks, deciding power and privilege

c. attempting to determine how a person performs tasks 
d. expressing, or enforcing, a model of the world

e. providing a major component of the work environment/ecology.

All these factors would usually be considered by social theorists to be important in ordering the workings of a society. ICT both interacts with social systems and becomes part of those social systems. As Orlikowski remarks, it is important to realise 'the diverse ways in which a technology is appropriated and utilized by workers, and the non-uniform manner in which it structures individual and organizational action'.6 Once technology is installed it may undermine the intentions behind it, and have unexpected and limiting effects on what can be done, while creating particular habits of technique and interaction. ${ }^{7}$ While technology plays its part in organising society, it is not necessarily harmoniously integrated with all social action.

I suggest that even if all the technical/scientific problems involved in ICT could be solved, disorder and disruption would continue to arise because ICT as an ordering tool produces disorder, in which the managerial politics that are clustered around implementation may attempt to override situational complexity, resulting in 'bite-back'. When ICT is changed (which seems to be a regular feature of the modern workplace), its new models and processes, which arise within regular failures of communication, a. have the capacity to clash with the necessary informal, emergent, and unrecognised structures of work, or b. are exploited for the benefit of a group or department, thus producing an ongoing sense of chaos and struggle. Social systems are always riven with differing groups, conflicts, disputes and status issues; with people having different understandings of work and what needs to be done. Hence, social orderings and software orderings often conflict, and an installation can be used to produce unwelcome change or resist encroachment. ICT can attempt to impose an unrealistic, standardised, harmony. People's previous experience of ICT projects may also lead to them being reluctant to co-operate. As such, ICT is always entangled in the ongoing politics of work, communication failure and the inadequacies of conscious modelling. Such disruptive and ambivalent factors cannot be left out of information society theory as they constitute a problem both for ICT effectiveness and evaluation, and for the society that goes on around it. 
Normally when writing academically a display of order is required to show competence, which is a problem when attempting to establish the ubiquity of disorder and unexpected events. A survey of ecologists by Doak et al. shows it is common for ecological systems to behave in truly surprising ways. ${ }^{8}$ However, these surprises were not reported because of the implication that these observations were uninteresting, bothersome, embarrassing, or not sufficiently well chronicled and understood'. ${ }^{9}$ In other words reporting surprise, or what looks like disorder, implies the writer is lacking in understanding. Consequently, regular unexpected 'disorder' is not usually part of what we discuss academically.

The idea that successful control over nature or people is a vital part of the scientific or technical project is common. Heidegger, for example, considers technology as a mode of framing, which controls and challenges nature, and strips away poetry and alienates us from an approach to original being. ${ }^{10}$ While ambivalent about technology, the main direction of his argument is to present its ordering as wholly bad because of its success, and he does not question the effectiveness of 'this stripping', despite a long history of similar objections to technology. Merchant equates technology with the successful, if violent, domination of nature and women. ${ }^{11}$ In her later writing she detects a move from control to partnership, but never really problematises the ordering effects of control.12

Ordering is also about the power to order. While Foucault's analysis of ordering procedures in medicine, psychiatry and penalisation clearly shows how some modes of ordering create the disorders which they then discipline, he presents very little exploration of how modes of ordering disorder themselves. Consequently, the web of power appears seamless, coherent and impossible to challenge, rather than selfdisruptive or vulnerable. Subjects tend to be conditioned, and self-conditioned, so as to be trapped. Although Foucault states 'where there is power there is resistance', the resistance seems to be encapsulated within regimes of power. ${ }^{13}$ There is no place where the power system appears to break down. He further implies that power involves subjugation and smoothness of fit.

Let us not, therefore, ask why certain people want to dominate, what they seek, what is their overall strategy. Let us ask, instead, how things work at the level of on-going subjugation, at the level of those continuous and 
uninterrupted processes which subject our bodies, govern our gestures,

dictate our behaviours etc. ${ }^{14}$

When power might look strained because of the awkwardness of the spectacle at the beginning of Discipline and Punish, it then shifts into something new, deleting messy years of history. In Foucault, power even becomes functionally homogenised:

Generally speaking, it might be said that the disciplines are techniques for assuring the ordering of human multiplicities. It is true that there is nothing exceptional or even characteristic in this: every system of power is presented with the same problem. ${ }^{15}$

People are to be made useful, and everything (school, family, medicine, prisons, factories and so on) is bent to the same apparently harmonious attempts to produce useful subjects. Foucault is more remembered for the image of the Panopticon than for discussions of its failure to be built. When mentioning the failure of prisons to prevent crime, Foucault argues for their success in producing less 'politically or economically ... dangerous-and, on occasion, usable' people. ${ }^{16}$ Again there is no real failure of ordering and no self-generated disruption.

Kendall and Michael argue that Foucault displays possible sensitivity to disorder in his distinction between contingent and practical 'techniques' and logical and systematic 'technologies', but this is not realised in the English-speaking world, with technology being the preferred term, and this is true of Foucault himself when speaking English. ${ }^{17}$ This could imply the distinction is not that important, or is easily lost. But even they do not suggest that Foucault is interested in how technologies may disrupt themselves or the organisations that implement them.

Cultural studies has made many valuable analyses of ordering in cultural workplaces protesting against the corporate domination of academia and art. Ferrell, for example, rightly argues that corporate managerial order disrupts work, and that technology 'will exceed itself, that it must fail its own rationality', but does not put this forward as a property of ordering, or of the interactions of technology, management and workers. ${ }^{18}$ This allows the implication that better management could remedy the disorder, which may not be her intention. Harney states:

management implies labour, and not just any kind of labour but organized labour, massified and industrialized in some form ... [therefore] The arts move from the workshop to the workplace. ${ }^{19}$ 
A smooth change of orders is implied, rather than a disordering or internally generated self-destruction. In a result unintended by the author, management appears to be overwhelmingly successful at ordering. Harney argues:

The social factory comes to subsume civil society and transform the struggles over neo-liberal governmentality outlined in Foucault's late lectures. The creative industries raise an even more sinister alarm. Civil society in all its morals, tastes, attentions and opinions becomes the site not only of control but of direct expropriation, all the more sinister because it does not collapse into categories of the economy but expropriates from the distance of governance. Occupying or sabotaging such a factory is no simple matter. But cultural studies distinguished itself in this space between economy and politics, in the hidden abodes, finding value and finding organization long before the creative industries. Now would be the time to remember this history. ${ }^{20}$

In this view, order seems almost inevitable and invulnerable. I would suggest we pay more attention to what we call disorder and to the ways managers produce disorder as a by-product of ordering. A disorder-centred approach might also lead us to ask how cultural workers make themselves vulnerable to the disorder of management.

In his criticism of management, Parker points to the common assumption that 'management is a precondition for an organised society', with all difficulties to be solved by better management. ${ }^{21}$ It appears that order must be maintained, and without management we would become disorganised victims, and chance and chaos would triumph. ${ }^{22}$ As a culture we produce books on the management of children, anger, daily life, disagreement, climate change, and so on. Management is ubiquitous, and 'in principle, anything that is problematic or chaotic is a target for management'.23 Therefore not doing management seems inconceivable or 'bad'. Although he argues that management crushes democracy, caring and responsibility, he does not suggest that management creates a disorder that undermines it or produces space for resistance.

—INFORMATION TECHNOLOGY AND THE PROMISE OF ORDER

In the so-called 'age of information', ICT is usually held to be essential for ordering and enabling organisations-which implies that organisations are often perceived 
as essentially alike. Similar management techniques are applied in government, business, voluntary organisations and universities. The supposed virtues of ICT and management can be seen as guiding myths for our time. Many governments, in particular, have assumed that ICT is inevitable, bringing increased efficiency: 'a new and better government, rational information planning, and empowerment of the intelligent citizen ... enhancing the access, transparency, efficiency, and quality of public administration'.24 ICT has been held to reduce hierarchy, encourage democracy and allow markets to work with maximum efficiency. In other words, ICT supposedly enables increased order and harmony. Despite the myths, 'studies have shown that the actual implementation of e-government initiatives has been disappointing'. 25

Bekkers and Homburg identify several parts to the myth of technological improvement which blend ITC with management:

a. ICT produces organisational renewal, giving the purified image of a new and better government'. 26

b. ICT is neutral and inevitably progresses, making access to services easier. 27

c. ICT integrates activities. ${ }^{28}$

d. The primary focus is the use of 'rational planning and management methods to accompany the introduction of ICT' ${ }^{29}$

While these myths are not impossible, the mutual involvement of order and disorder suggests that ICT is political, not neutral; that it expresses (or aggravates) existing conflicts, can make activities more complicated and more prone to 'dis-integration', and that rational planning (if it occurs) acts to direct the installers of ICT from researching what anyone does, or needs to do, into irrational hope and abstract plans with no empirical base.

Significantly, Bekkers and Homberg claim that the final 'goal of integrated electronic service delivery ... leads, in practice, to serious integration and coordination problems'. Different organisational departments have their own histories, procedures, needs and frames of reference, and may not respond positively to attempts to standardise them. Indeed uniform order may disrupt ease of action..$^{30}$ 'Standardization and integration may intensify existing dependencies and enshrine these dependencies in the technology ... Consequently, excessive 
integration fuels interorganizational tensions and conflicts.' ${ }^{31}$ The ordering can produce disorder. Standardisation also requires a lot of 'tinkering' or 'work arounds' to cope with the randomness and contingency of actual life.

Many business leaders also exhibit a millennial attitude towards ICT. The inside cover reviews of Tapscott's Digital Economy includes remarks from people such as Paul Allair, then CEO of Xerox, who writes 'a new generation of business leaders must seize the promise of the digital revolution and use it to build a new economynot just for the success of their own enterprises, but for the success of the new world' (italics added). Frederick Smith, CEO of Federal Express, writes: 'emerging information technology ... must be understood and finessed by any company expecting to be successful'. Terry Waters, vice president of the Gartner Group, says 'the new information technology is becoming the critical enabling factor for change'; implying the world is in flux but ICT allows mastery. ${ }^{32}$ Elsewhere, J. Bruce Harreld of IBM warns of organisations being unprepared for the ICT revolution. IBM turned around its fortunes by 'accelerating technology innovation'. He claims that ICT helps organisations evolve, be responsive and adapt; it brings order to chaos. Harreld celebrates knowledge sharing through ICT, which frees the organisation from being dependent upon knowledgeable staff. This implies that inherent in this order is the apparent interchangeability of staff and machines. Organisations that do not act similarly, he claims, will become extinct. 33

The feature article of the November/December 2010 issue of Oracle Magazine, published by the Oracle Corporation, gives 'awards' to: 'Leaders and teams who deploy technology to give their organizations a competitive advantage, improve customer satisfaction, and increase profitability.' Despite the years since the previous remarks, the claims put forward by managers about ICT are surprisingly similar. Alexandre Vasconcellos, CIO of Grupo Pão de Açúcar, Brazil's largest retailer, said the ICT project would 'enable us to speed up our infrastructure, systems, and business processes'. A pilot project had shown 'an opportunity to eliminate seven days' worth of inventory' and sales had increased. 'Completing the rollout to all the company's businesses will make it possible to save an estimated US\$300 million'. Peihui Wang, general manager of the information management department at China Resources said Oracle was 'helping to establish comprehensive ICT solutions that strengthen the fundamentals of our company'. The company's 'pace of growth 
requires an agile and enterprise-oriented ICT infrastructure ... [Previously] the overall ICT infrastructure was very fragmented and could not support the company's fast business growth.' Presumably ICT was, up to that time, not so good, but it will be in the mythic future. Yasutomo Fukui, CIO of Panasonic, claimed ICT allowed his employees to focus on innovation and business opportunities instead of on technology details. 'Standardization of our infrastructure, processes, and data will serve as a common language throughout our company so the ICT organization can orchestrate a true business collaboration between management and staff.' Harmony is supposed to result from ICT. ${ }^{34}$

It is not just the state and business which is influenced by the myth of ICT as an ideal ordering method. Rob Kling points to what he calls 'computerization movements' (usually of computer professionals) which are based on similar utopian or millennial myths. ${ }^{35}$ Indeed, in the 1990 s the story was often that computerisation was proceeding too slowly and so, Kling writes, 'many professionals and managers are adopting computing systems rather rapidly, while they often puzzle about ways to organize positive forms of social life around them'. ${ }^{36}$ This lack of concern about social life may occur because these are movements 'whose advocates focus on computer-based systems as instruments to bring about a new social order' ${ }^{37}$ As ICT, in its myth, is an ordering tool, the actual order is set in a mythically guaranteed future, and the current mess (perhaps resulting from ICT) just proves the need for better ICT. The reordering of work seems inevitable and beneficial for particular people, who need no knowledge of how the current social system works in order to 'improve' it. 'Human intention, pluralities of interest, or large scale conflict play a minor role in these predictions of substantial social transformation'.38 Hence computerisation movements claim no one 'loses from computerization; and uncooperative people are the main barriers to social reform through computing'. ${ }^{39}$ This act blames the failure on those the system fails most acutely.

In government, in business and among computer professionals, the driving myth of ICT is that it leads to increased efficiency; better information; rational planning; improved quality; lower costs; integration of activities, organisations and knowledge; standardisation; harmony; increased knowledge; increased innovation; and increased adaptability, flexibility and responsiveness. ICT is said to be important for success, lowering dependence on staff and creating ease of 
management and superior organisations and orders. It is essential for survival and making productive order and sends a message to others that 'we innovators' are on top of things.

\section{-SOFTWARE FAILURE}

Despite these myths, failure in software and ICT generally seems rampant and needs to be taken as a fundamental part of the information society, and not just as a passing aberration. Saran describes a survey of 450 ICT directors across Europe, of whom 73 per cent said they had suffered major faults in their ICT systems, 43 per cent said poor software quality led to a substantial drop in staff productivity and 45 per cent said poor software quality had damaged the company's image among clients and prospective clients. ${ }^{40}$ Huber reports another survey in which ' 54 per cent of projects failed to deliver on the planned-for functionality' while 9 per cent were abandoned and only 16 per cent of the projects 'hit all their targets (budget, schedule and scope/functionality)'.41 El-Emam and Koru report two years of web surveys, saying that: ' 26 per cent to 34 per cent of ICT projects fail'.42 Joe Harley, CIO of the UK Department for Work and Pensions, estimated that only 30 per cent of ICT projects succeeded.43 Many systems work most of the time but occasionally have marked failures, such as with the Bank of Queensland eftpos terminals at the start of 2010, or the Qantas booking system which crashed in November 2009 and January 2010.44

Whether something works can be difficult to decide. For example, Kling points to the ambiguities of productivity increase. ${ }^{45}$ People can use ICT to generate more numerous, ever more detailed, improved and beautiful reports with the added control and order they can suggest. Yet these capacities may lead to what others see as 'time wasting' or as generating unneeded non-functional work. ICT also allows the shifting of work elsewhere onto other workers, as when everyone ends up having to do their accounts rather than have them done by the accounts or finance department (something that appears to show the relative power and valuation of work within the organisation and hence both produces and displays conflict). Work that uses ICT becomes dependent on ICT and is disrupted, or even paralysed, by malfunctioning computer systems and by models that do not match the work required. Regular upgrades of software to keep up with other organisations, or to 
keep the support of the software supplier, encourages the frequency of management restructures, and constant upgrading increases the necessity for time spent on retraining, and of the likelihood of being affected by incompatibilities between systems and so on. These disruptions are not simply failures, but are consequences of these particular ordering systems, which are then usually 'fixed' by even more intense ordering of the same type, which lead to further problems which also must be fixed.

Disorder does not only arise through failure, but through success. The massive power consumption of data centres generates significant greenhouse emissions and financial costs. ${ }^{46}$ Similarly, if ICT did not make data collection so efficient, we could not be defined by our data trails, and have our identities abducted so easily and so on. ICT is a major source of disruption because of its success and ubiquity.

If failure and disruption is a constant, recurring and widespread feature over sixty plus years of computer usage, then this does not result from individual mistakes, but is part of the social system itself.

-WORK AND ITS ENDS

To begin the investigation of these disorders I conducted twenty-four, roughly onehour-long, interviews of ten women and fourteen men who have experienced different software installation at various levels (business analysts, members of IT departments, software testers, programmers, project managers and workers). I also sat in on a major organisational software upgrade. Each interview subject has been anonymised and assigned a number within curved brackets, for example (1), so as to allow readers to trace opinions through the text, and to sometimes distinguish similar but separate cases. Occasionally the quotations have been slightly altered to provide clarity, or to protect the people and organisations involved. All the interview subjects volunteered for the interviews, which might imply a disproportionate level of dissatisfaction, but several subjects started the interviews claiming they had little experience of software-related disorder but then proceeded to describe such selfrecognised disorder. Despite the small sample interviewed, interaction with people in daily life suggests the results are not unrepresentative. Many of the interviewees have had experience of more than one 'bad installation', and expected many more such experiences. 
All the interview subjects made their living through using ICT, and use it extensively in their non-working lives. Some of them programmed for pleasure in their spare time. They worked in the private and public sectors, and in large and small companies. Despite the frustration recorded here, every person interviewed expressed enthusiasm for their work. Almost all articulated a degree of puzzlement about the regular failure of software. For example, the manager of a software development team (7) said: 'there's a huge amount of frustration I'd say involved in using computers in general. It usually comes from, I suppose, unexplainable things that happen on the computer that stop things from working in a normal way.'

Nearly all interviewees said that computer or software failure was common, and they described their own or others' reactions to such failure in terms of intense feelings of anger, panic, or being overwhelmed. One person (21) described the loss of their data as making them ill. However, all those interviewed continued their struggle to make things workable, and to find work-arounds that would allow them to continue. An ex-business analyst (6) remarked: 'I'm surprised sometimes at the level of tolerance that users have. I'm thinking of different projects where users were waiting for solutions and they haven't had the solution or they've been given a half baked solution and they've been okay with doing a work-around for a long time.' Workers develop tolerance for failure and the ingenuity and ability to get around it.

Here, I will discuss only three issues which arise from these interviews. First is the existence of informal networks at work, which are primarily focused on workarounds and help, and act to make technology and work functional and sociable, rather than coldly 'rational' or 'efficient'. This is both a form of resistance and way of getting work done. Second, I discuss the generalised failure of communication in a management hierarchy; third the failure of models and requirements engineering. These issues all intertwine (often around group conflicts and communication failure), so that one point looks forward to the other, and each affects the other. The disruption produced by management promotes informal compensatory networks and conflicts, which in turn promotes the inaccuracies of models, which in turn increases the failures of management. Any starting place is arbitrary. 
Several interviewees $(7,10,11,14,18)$ seemed to be of the opinion that the disordered systems were often kept working by unofficial 'work-arounds' (that is, by self-worked-out tricks and kluges), or by social networks within the workspace. These informal networks are not recognised by management or by the computer system. While they are spontaneous forms of ordering produced by people using the system so as to overcome its problems, by the hierarchy they become taken as if they were disordering the ideal of the computer and managerial system. Showing the importance of such networks, a middle management user (9) reported a merger of two departments that resulted in a new intranet for data storage that was so complicated that no one actually used it, despite both departments previously having well-used intranets. Upper management apparently had no idea there was anything wrong with the new system until they conducted a formal evaluation; largely because management never used the system themselves, and were completely unaware of how it functioned. Workers had kept the system working by finding data, documents and templates, through phone calls and emails to other workers. Such social adaptations were not uncommon. While this may be seen as creative, the other side of human adaptation is that 'people build up a tolerance ... when they see no other option and resist improvement' (6). People may feel threatened by change, or attempts at improvement, which potentially disrupt their hard won and precarious functionality, and demand the effort of building new informal, perilous and unrecognised networks to make work possible.

Sociable networks of help get built around these work-arounds and these networks are compounded by failures in formal help services. Almost nobody expressed satisfaction with help-desks, unless they were organising help for others. Providing help is clearly difficult; some interviewees thought that people on help desks assumed they were idiots and made blindingly obvious suggestions they had already tried, while others considered that help desks used technical jargon they were unfamiliar with. This suggests that help desks are standardised in their response to users, seeing them as ordered and uniform, and thus produce disorder. Others suggested that the people on help frequently did not understand the system, or the work to be done with the system, either. One person (10) suggested that if you rang their help-desk too often then they would consider you incompetent, 
blackball you or brand you as a troublemaker. This could also, the interviewee thought, lead to bad information about you leaking out. People on help desks, in my experience, frequently tell tales to each other, and to anyone who will listen, about idiot users. Disorder and conflict arises between formal help and those being helped, through differing knowledges, different expectations, borders between groups, bad communication, and the contingency of problems.

While people (such as (1)) could say that inbuilt help systems were 'fantastic' or 'incredible', they could also say it was 'overwhelming to even look at it'; especially if they had a client waiting while they searched for help. Spending time searching for help can make the person look inadequate, so may not be done, and the action not be undertaken. During the course of writing this article, my computer was silently reconfigured, and the online help I needed to return to my original preferences in one program did not work with any of my browsers. Probably, the designers thought online help was easier to keep updated, but that ordering, itself, led to update and integration problems. One programmer (15) reported that his workplace's problem reporting and help software was so extremely complex it was itself a problem but, despite his relatively high position in the company, he was not able to get it modified.

Due to these problems with help desks and automated help, most interviewees seemed to prefer to either work things out themselves, or informally contact others in the organisation and ask them. Networks of contacts came into play, as different people discovered different techniques. One interviewee (1) remarked that sometimes they were able to teach other people things and 'I think that's obvious, but to them that's been a revelation.' Interviewee (9) said that they used personal networks to try and solve problems and organised 'reference' groups to pass on problems to the right people. In some situations people felt able to go to their managers for help, and in other cases supervisors were considered useless as they did not use the programs, or were more likely to punish questions and the appearance of problems. However, these unofficial help networks could be precarious as people might be too busy to help-judging the right moment is important (24) - and they can be blocked by management; as (15) reports: 'it's probably most accurate to say that it's no longer part of the culture for someone to put themselves in the I know everything position and I can help you sort things out 
... they're much more accountable for their time and the I can fix everything guy isn't making his manager any money'. Imposing economic 'rationality' can disrupt the human systems that allow the making of money.

In general, it seems that management either does not value these informal systems, regarding them as pointless distractions-perhaps in the same way as managers appear to worry about workers using the internet to socialise-yet people gain status, pleasure and meaning through such unofficial networks and will object, or be dissatisfied, if they are disrupted by another (new computerised) order that has little relationship to what they do. Indeed, other work systems (not just help) may depend upon these informal contacts, and disrupting them will produce disorder elsewhere. For example, one person reported that their company had flourished because of unofficial exchange of ideas between different departments, helped by 'fan-based' email lists and meetings. Management felt that increased security was needed to protect the firm's intellectual property and prevented this discussion. As a result, communication and the exchange of ideas slowed dramatically. The interviewee was certain that work was now being duplicated rather than coordinated across departments.

In summary, it appears likely that in the ongoing chaos of work, people often keep the system working with fudges and work-arounds, gained from contacts in the organisation. People form unofficial networks, serving many functions, and may resist changes to their hard won stability-especially changes introduced through new computer systems. Strata in the hierarchy often mean that management never has to confront the non-working software, and are only told what they want to hear, because the consequences of saying anything else is, possibly, not good for the teller's career. People may avoid the help desk, as they likewise feel the help is contemptuous of them, either giving more technical data than they need or treating them as if they were stupid. This gives more reason to form informal networks for help-even if the management is hostile to such connections. Furthermore, these informal networks tend to increase the ignorance of management and the IT department as to the kinds of problems people face, and so managerial decisions and directives, based on inadequate information, produce further difficulties and disorder. Managerial order may be hostile to the work order which has developed and kept the organisation alive. 
Managers are not a uniform or united class. There is almost inevitably conflict and concealment occurring between managers, and between managers and those they manage. Managers fight over the distribution of internal resources, claims to knowledge (as a high position is generally assumed to involve greater knowledge or skill), and shield themselves from attacks which could be damaging to their survival in the organisation. Conflict between managers can affect all the workers including the people writing or installing the software, or gathering requirements. People interviewed insisted that software installation can be embroiled in this conflict. Installation can arise from what is seen as warfare between managers, being used to extend what one department thinks is the right solution into other fields or domains. ICT is not just a tool of conflict between managers and workers, but between managers and between departments.

In hierarchy, especially where there is the prospect of punishment or reward for going along with the superior, communication will not be free and open, and disturbing messages will be ignored. 'I was approached by a member of the steering committee who was concerned that the project didn't appear to be progressing and I expressed my views as to what I thought was going wrong and I was subsequently asked by the project manager to leave the project' (14). Not to be perceived as 'positive' (or as agreeing with superiors) may be taken to imply a person is not fully engaged or not 'pulling their weight'. ${ }^{47}$ As Suchman and Bishop report: 'Labels for the "resistant" agents included agents who have "plateaued", "flatliners", "pond scum", "slugs", "men of extinction" or "sleepers and squeakers"'.48 Objection can be seen as obstruction. People may have to act within a managerial millennialism of forced harmony, which ignores the realities of work and world. Some interviewees remarked that workers were so frightened of losing their jobs that they would resentfully accept almost anything, even moving their house to keep work. If this fear is linked with the possibility of punishment for accuracy, then explorations of what is needed in software will suffer. Workers will try and guess what they are meant to say, try and prevent their possible removal, or be ignored by those collecting the data as management has other plans. One business analyst (20) mentioned the benefit of temporary workers as they have less knowledge of how things used to be, and presumably less role in the spontaneous networks and 
organisation that have arisen, and are hence less resistant to change. Another person (14) lamented the common decline of the middle manager with the coming of the 'level organisation', as middle managers were the people who bridged upper management and workers, and who communicated with other middle managers and thus had a wide understanding of how things actually operated from a number of perspectives. They were therefore useful in providing software requirements. Other people $(1,2)$ spoke of losing easily found local knowledge when people were removed as information sources and replaced by data banks which only stored information that managers thought was important. Furthermore, distance from and lack of involvement in the actual work can hasten closure of communication in the assumption of understanding. The less interaction the management or requirements engineers have with people in the organisation, the more likely they are to think that they have understood the workers. As Suchman writes, 'the further removed we are from the work of others, the more simplified, often stereotyped, our view of their work becomes'. ${ }^{49}$

A software manager I interviewed recommended that staff should always be told that they will not suffer any major change as they will resist the installation. This attitude leads to management by deceit, and consequent suspicion of deceit, which increases the possibility of workplace disruption, and failure of information transmission. Certainly it would increase the sense of paranoia and dislocation among people who never quite feel they know what management is actually doing. People recommending this kind of procedure had a great suspicion of workers, and saw them as obstructing the process of management, which again furthers the atmosphere of distrust, and provides a scapegoat for the institutionalised failings of management. Because of these obstructions to communication, it is often more appropriate to talk of a power/stupidity nexus than a power/knowledge nexus. 50 One person (6) argued that software change in the public service was generally smoother than in the private sector because staff had greater job security and ran less risk with management when reporting failings, and suggesting improvements.

ICT can also be seen as warfare against staff, an attempt to extend managerial control, extend work, diminish autonomy, get rid of people, outsource, redistribute profit away from workers, and get workers to do the drudge work that managers, or another department, used to do and so on. As one person said after an installation: 
'There's definitely less autonomy and less power and that's frustrating and annoying' (11). Another interviewee (18) reported that 'the business has been taken over. With the old system we had a lot of representation, a lot of autonomy and we had a lot of say, but the new owner just wants to streamline everything. The software was changed without consultation, just rolling in what they used elsewhere.' I asked if the changes in software were related to a change in management styles, and was answered: 'Yeah, management styles and management structure ... the company which has taken over is more focused on the financial rewards than on service standards. So it feels like the standards are being compromised for profit.'

If management generally has restructuring mania, which is anecdotally common, then it will disturb the workers' informal networks and the ways things are done in the workspace. A programmer who managed research, and was enthusiastic about his workplace, said that, in his opinion, after a series of software installations and management change ventures, 'trust from the engineers to the managers has dramatically lessened. There have been a whole raft of different changes for different reasons. Some of them quite significant with significant impacts on the staff. Everyone in the organisation pretty much is suffering change fatigue' (11). Consciously decided management change can initiate side effects, which may destroy workplace functionality as much as software failure does.

Apparently self-destructive management patterns can be applied as when 'there is actually no incentive for people to finish anything because, well, they may be made redundant' (20). I have even heard of a successful multinational company telling its workers they would probably be dismissed, but should get on with training their outsourced potential replacements in using their software. According to a further interviewee, another well-known multinational sacked nearly all the support staff in its new acquisition and six months later the promised outsourced support had not been trained, leaving its highly experienced development and technical staff doing telephone support over 12-hour days. In all these cases there seemed to be no hope among the interviewees that management would listen to, or welcome, protests.

Despite these experiences of disorder, those interview subjects who managed software projects were almost uniformly optimistic about their projects, even when 
many difficulties appeared during the process. Problems tended to be blamed on others, whether management, workers or customers. Technological 'improvement' was nearly always seen as a general improvement. 'We have to keep to date, to keep up with competition' (21). 'This suite will allow [the organisation] to become a leader in their field' (19). 'Work practices can always be improved' (22). There often seems to be faith that simply upgrading the system will prove to be an effective cure for whatever ails the business or, at least, that such an update is necessary for life in the 'modern world', or to demonstrate to other businesses that you are on top of your game. Information technology opens the way to millennium, even if it is recognised that problems are always experienced.

\section{- REQUIREMENTS AND MODELS}

There is a sub-discipline of software engineering, known as requirements engineering. This involves gathering the software 'requirements'; that is, trying to find out what the software should do and the best way to implement it. Requirements engineering is about building models of the workplace and the processes of work. There are many well-established procedures for this, including the simple directive to talk to the 'right people'. However, 'the majority of these techniques are rarely if ever used by practitioners. Solutions appear to be available, yet we continuously fail to make use of them.'51 This is born out by the interviews and this section explores the necessity of this failure.

Absolutely none of the people interviewed thought they had a satisfactory requirements process in the installations they had been involved in. Staff, who knew what the work involved, were usually left out of the planning process, as reflected in the following comments. 'It's just really frustrating I think as a staff member we don't kind of know what the thought process is behind doing these things' (2). 'When these decisions come from up high without consultation, people have less trust in the executive [and for major] system upgrades or integration projects or any of that, they're all coming from top down' (6). 'The decision is made at a higher level and they just get the task of rolling it out regardless' (7). 'There's nobody in my particular area that was really quizzed about what they did' (2). 'I did write a fair few requirements documents and reports and whatever. The problem is that people 
like to have this information but don't do anything with it' (6). 'We just had to accept what we were given' (1). As one interviewee said:

We didn't feel as though that the requirements had been gathered properly ... A common problem I find with internal IT groups, such as were responsible for doing this implementation, is that they don't gather the requirements from the internal stakeholders before they implement these systems. The decision is made at a higher level and they just get the task of rolling it out regardless. (7)

Such remarks imply that there is, despite claims to the contrary, little effort made to gather useful information about how an organisation works, or the tasks faced by workers, before the software is written or installed. If this is the case, it may not be surprising that the software fails to provide people with what they need.

As already suggested, communication in the hierarchy of business is difficult. Requirements engineers 'just speak to the wrong people': to managers instead of workers (7). And from (8):

You've got IT people working out categories for work they don't do and eventually they have to, of course, employ someone from our area to tell them what those categories might be. They don't do this when they bring things in because they really don't think that we on the floor have any idea. They assume they do.

Similarly, a project manager and programmer reports an occasion when 'the project sponsor ... did not want any interaction with the clients before deployment':

This person said, I know everything that you need to know, you talk to me if you need to know what the system has to do and I'll tell you and I'm very impatient for this to be finished, that's why I don't want to be talking to people out there because they'll only slow you down. (14)

Knowledge is assumed, perhaps because if it is not the managers in question would have to admit ignorance and risk status.

This seems particularly the case in mergers. "The merger project was announced from on high. There was absolutely no attempt to find out what users did with the system or needed to do with the system. It was just assumed to be a good thing to go ahead' (9). 'It was very much about us fitting with [the external company's] software. It wasn't about them coming to [us], finding out what our 
needs were, what we could do. It was about us fitting with their software. There is this thin veil of consultation, but it's meaningless. It's absolutely meaningless' (10). One interviewee described a case in which a company decided to blend its offices in two different states. Given the communicative relations between workers and management, this reorganisation was primarily seen by staff as a money-saving venture likely to cost them their jobs and thus they were not particularly helpful. The scope and instructions for the new software were provided by senior management, but they 'didn't understand the nature of the work and you had a company based somewhere else that was taking over a new location and they didn't understand the customers' (6). The result was a mess, based upon assumptions of common standardised practice. Several people in this kind of condition suggested it was more important for the new management to display power than to be effective, but perhaps for management the technology, ideally and according to the myths, must work without any necessity to learn about local conditions. Furthermore, when management has decided to engage in reformation of the workplace, to change and improve what people do, it has no particular interest in finding out how things are currently done; these inefficient methods are to be superseded by the future ICT utopia, and current methods must be inefficient as they are being superseded. Reorganisation justifies itself in terms of a state which does not yet exist and this is tied to the unequal communication and assumptions of knowledge that produce the frustration in those so organised. Only one interviewee reported any attempts by their management to check whether the new system was better than the old. The guiding myth of ICT as a force for progress guarantees the value of the work.

In some cases the requirements seemed to be gathered from the business rules, which did not correspond to what the business was currently doing as workers had adapted to the changing environment. Indeed one business analyst (20) reported that managers and experts could get quite annoyed if you queried the way they, or the rules, said work should be done or was done. Requirements engineers could obviously find it easier to agree with those 'experts' and managers rather than continue their queries. An installation that runs over time and over budget with plenty of requirement changes might be quite profitable, and thus could reward the person who does not insist on ideal requirements principles enough to anger their employers. 
Requirements can be easily disrupted by the politics in the workspace and between departments. One person in management (24) told of how a whole department was marginalised and forced to use what for it was non-functional software, while being blamed for not cooperating with the process which more or less worked for everyone else, in particular for the Finance Department who had instigated the upgrade and had considered the scapegoat department old-fashioned and inefficient beforehand. Another person told of how management had 'made a working group and sort of got at the things that people were annoyed with in the old system and put together the features of the new system'. The interviewee continued:

But that was only one factor that went into it. I think the things that determined the choice more were other factors like support, or how well they could maintain it, or how well it integrated with the parent company's financial systems. I think they were mainly concerned with how well it supported the functions for the financial people in the company rather than for the other people. (11)

What counts as important is a political decision in itself. The result can emerge from power struggles within management, and it was also alleged (19) that some departments may deliberately attempt to sabotage the process to make the project sponsors look bad.

In most organisations, different parts of the workspace will have differing or competing requirements, and different or competing meanings and values. They are not uniform. Thus one department may wish to supervise another, and the other may wish to escape supervision in order to get on with its job, in either case there is no general harmony. Too much control prevents flexible adaptation to the environment, or reduces all responses to the countable or processable. Too little control means that a group may have no responsibilities. These competing organisational requirements mean there is usually a political evaluation of the relative importance of the work of the various groups and of the amounts of money and time that can be spent sorting out all the problems, or in discovering them in advance of the actual installation. This will favour some at the expense of others and produce disorder from disfavoured's point of view.

Furthermore, models of work are political, as they attempt to enforce particular modes of behaviour, communication and power, and thus represent only a possible 
set of behaviours as valuable, irrespective of their real value. Categories of user, as defined by management, may not correspond to real functional divisions in the workspace, or to what users actually do. Similarly, categories of work or produced object, under the business rules may not correspond with work as it is done. Neither may categories of customer. This diverts energy into working around the categories. One person (10) described how it was impossible to compare entries in their old database with entries in the new database because the two were differently categorised. Similarly, the implementation may be geared to engineer increased managerial control over workers (which is a common suspicion). This may be disastrous for workspace functioning, as workers are prevented from doing things which are necessary, or which forge relationships with customers or other companies, or simply make the work more pleasurable.

Therefore, if requirements are not collected accurately, it is because of the inevitable politics and communication obstructions in the hierarchical workspace. ICT is about standardisation and uniformity of need is assumed or enforced, it is not considered necessary to talk with employees, or explain to them what the project is about, and it is assumed that resistance, or disagreement, is evidence of incompetence. Within this framework it seems less dangerous for requirements engineers to work out requirements from first principles, or from talking to managers, or by simply making requirements fit off-the-shelf software. All these methods assume that hierarchy and work is transparent so that people higher in the hierarchy, or remote from the work, actually know what needs to be done and the kinds of context in which it is done. If the hierarchy is already punitive, or allocates rewards for agreement, or if people live with a degree of paranoia (and space for fantasy and blame), then knowledge of how other parts of the organisation work will be distorted. Accuracy of communication is inhibited by these power differentials. This may not depend on the number of levels of hierarchy, but on the difference between levels. Furthermore, as some ICT people argued, gathering requirements adds to people's work, which may make writing the software more expensive, and so a case can always be made for not gathering them fully.

In summary, ICT can trigger previously existing social conflicts, and create new ones, and this affects accuracy of information and distribution of blame..$^{52}$ Even in a relatively harmonious workspace different evaluations can lead to friction. There is 
very little incentive for requirements engineers to fight against the managerial view of what needs to be done, and what needs to be done is going to be different from what is done now and hence it can always be suggested that current practice is of little value.

\section{-ENDPOINTS}

ICT is an important managerial tool for ordering organisations and work, yet ICT projects fail, or fail to live up to their promises, regularly. The myths of ICT promise a new social order, in the eyes of some faction or other, sometime in the future and ignore the social clashes and disjunctions present in social systems, and become a form of enforced millennialism. Even when they work, success can bring its own problems.

ICTs can be difficult to evaluate, due to conflicts over what constitutes success, and because allocating blame for failure is political and caught up in the existent conflicts of the system. The regularity of difficulty suggests that it is not just particular managers, or particular worksites, who are to blame but the systems of ordering that are employed everywhere.

In these ordered, and ordering, environments there is no guarantee communication will tend towards accuracy. Managerial hierarchy inhibits accuracy and knowledge, producing a power/stupidity nexus, which is continually reinforced. This failure of communication and ordering is implicated in the failure of requirements processes. Often it appears that there is little encouragement for a long-term and costly attempt to find out what people do, and the idea of technological reform of the social order means that there is probably little interest in what people currently do; it is the ideal, rationally imagined, efficient and profitable future that counts. ICT restructures can also be driven by conflict and power plays in the organisation, which promote even less interest in what those being taken over actually do. The aim is not improvement, but to get people to do something. People who protest or point out problems can be made scapegoats and may appear to risk losing their jobs. Association of status with knowledge confuses the transmission of knowledge. As a result, requirements engineers and project managers tend to speak to the 'wrong people'; that is, not the workers with knowledge, but to those that hire them. Even if they do speak to the people involved, 
then because of the communication and power issues this may not be seen as anything other than a deceit by the workers, and the workers may have little incentive to give accurate information anyway. People can try and deceive each other as part of the politics and rhetoric of survival within that organisation, especially if the failure of ICT is generally seen as resulting from uncooperative people, rather than from the organisation itself.

After the installation, informal networks can appear around the problems that arise, and these networks can come to serve other functions which are useful to work and to people's lives at work. These networks can be seen by management as evidence of disorder and needing control, while from another point of view they could be seen as the order which arises from the disorder inculcated by management, or generated by the ICT. These networks may cause further problems for managers as the distribution of power, work and responsibility becomes even more unclear.

In these senses, order and disorder are mutually implicated. Ordering techniques create their own disorder; people may use this disorder to justify further ordering ventures in a never-ending spiral, which may take energy away from more important activities. The driving myths of information technology as neutral, and as always producing organisational improvement, efficiency, flexibility, adaptation, uncluttered standardisation, transparency and improved communication, are over simple. However, the myths that only uncooperative people are the problem, that the flux of the world can be successfully and thoroughly ordered, that the future is here now, that everything can be integrated and standardised, and that systems can be managed and conceived in purely rational terms may be positively harmful.

The information workplace, as presented here, is not a place of accurate knowledge, smooth exchange of information, or rational management, but of active misunderstanding, obstruction of knowledge, organisational chaos and informal recoveries and resistances. This should lead us to look at information society theory, in terms not of the orders of society and of recognised working knowledge, but of it's neglected, or repressed, others: the disorders of society, the ongoing failure of management, the ongoing failure of networks and ICT, and the actuality of much knowledge being distorted, miscommunicated, ignored, or structured by myth, political rivalry and rhetoric. 
Jonathan Paul Marshall's writings currently focus on the social importance of disorder, especially in computing. He has published an ethnography of an internet mailing list called Cybermind: Living on Cybermind: Categories, Communication and Control (2007) and an edited collection of papers on Depth Psychology, Disorder and Climate Change (2009). A forthcoming book, Disorder and the Disinformation Society: The Dynamics of Networks and Software, co-authored by James Goodman, Didar Zowghi and Francesca Da Rimini, explores themes of disordering technologies in greater detail.

\footnotetext{
-NOTES

1 Peter Marshall, Demanding the Impossible: A History of Anarchism, HarperCollins, London, 1993. 2 M. Berg and S. Timmermans, 'Orders and Their Others: On the Constitution of Universalities in Medical Work', Configurations, vol. 8, no. 1, 2000, p. 31-61, p. 31.

3 Ibid., p. 36.

4 Ibid., pp. 45, 52.

5 Manuel Castells, 'Materials for an Exploratory Theory of the Network Society', British Journal of Sociology, vol. 51, no. 1, 2000, pp. 5-24, p. 15.

6 W.J. Orlikowski, 'The Duality of Technology: Rethinking the Concept of Technology in Organization', Organization Science, vol. 1, no .1, 1992, pp. 398-427, p. 401.

7 Ibid., pp. $412 \mathrm{ff}$.

8 D.F. Doak, J.A. Estes, B.S. Halpern, U. Jacob, D.R. Lindberg, J. Lovvorn, D.H. Monson, M.T Tinker, T.M. Williams, J.T Wootton, I. Carroll, M. Emmerson, F. Micheli and M. Novak, 'Understanding and Predicting Ecological Dynamics: Are Major Surprises Inevitable?', Ecology, vol. 89, no.4, 2008, pp. 952-61.

9 Ibid., p. 956.

10 Martin Heidegger, 'The Question Concerning Technology' in Martin Heidegger: Basic Writings, ed. D.F. Krell, Harper, San Francisco, 1977, pp. 283-317.

11 Carolyn Merchant, The Death of Nature: Women, Ecology and the Scientific Revolution, HarperCollins, New York, 1990.
} 
12 Carolyn Merchant, 'The Scientific Revolution and The Death of Nature', Isis, vol. 97, no. 3, pp. 513-33. Cyborg theory with its dislike of boundaries, not only does not problematise order, but disrupts resistance to management by ICT and the disordering of cultural work, see Jonathan Marshall 'The Intranet of the Living Dead: Software and Universities' in Zombies in the Academy: Living Death in Higher Education, ed. Ruth Walker, Christopher Moore and Andrew Whelan, Intellect Press, Brighton UK, 2013 (forthcoming).

${ }^{13}$ Michel Foucault, The History of Sexuality, vol. 1: An Introduction, Allen Lane London, 1979, p. 95.

${ }_{14}$ Michel Foucault, Power/Knowledge: Selected Interviews and Other Writings, 1972-1977, Pantheon, New York, 1980, p. 218.

15 Michel Foucault, Discipline and Punish: The Birth of the Prison, Vintage, New York, 1977, p. 218.

16 Foucault, The History of Sexuality, p. 97. Emphases added.

17 Gavin Kendall and Mike Michael, 'Order and Disorder: Time, Techology and the Self', Culture Machine, InterZone, November 2001,

<http://www.culturemachine.net/index.php/cm/article/viewArticle/242/223>.

18 Robin Ferrell, 'Income Outcome: Life in the Corporate University', Cultural Studies Review, vol. 17, no. 2, 2011, pp. 165-82, p. 180.

19 Stefano Harney, 'Creative Industries Debate', Cultural Studies, vol. 24, no. 3, 2010, pp. 431-44, p. 432. 20 Ibid., p. 443.

${ }^{21}$ Martin Parker, Against Management: Organization in the Age of Managerialism, Polity Press, Cambridge, p. 3.

22 Ibid., p. 4-5.

23 Ibid., p. 7.

24 V. Bekkers and V. Homburg, 'The Myths of E-Government: Looking Beyond the Assumptions of a New and Better Government', The Information Society, vol. 23, no. 5, 2007, pp. 373-82, p. 373.

25 Ibid., p. 373.

26 Ibid., p. 375.

27 Ibid., p. 377-8.

28 Ibid., p. 377 and passim.

${ }^{29}$ Ibid., p. 378.

30 Ibid., pp. 375-7.

31 Ibid., p. 379.

32 Don Tapscott, The Digital Economy: Promise and Peril in the Age of Networked Intelligence, McGraw Hill, New York, 1996.

33 D. Tapscott, A. Lowy and D. Ticoll (eds), Blueprint for the Digital Economy: Creating Wealth in the Era of E-Business, McGraw Hill, New York, 1998, pp. 62-75. 
34 D. Kelly, 'Editors' Choice Awards 2010: Delivering Innovation', Oracle Magazine,

November/December 2010, <http://www.oracle.com/technetwork/issue-archive/2010/10-

nov/o60eca-176293.html>.

35 R. Kling and S. Iacono, 'Computerization Movements and the Mobilization of Support for

Computerization' in Ecologies of Knowledge, ed. L. Star, SUNY Press, Albany, 1995, pp. 119-53. See also

Rob Kling, 'What Is Social Informatics and Why Does It Matter?', The Information Society, vol. 23, no. 4,

2007, p. 205-20.

36 Kling and Iacono, p. 119.

37 Ibid., p.122.

38 Ibid., p. 136.

39Ibid., p. 137.

${ }^{40}$ Cliff Saran, 'Software Failures Damage Business', Computer Weekly, 27 May 2003, p. 5.

${ }^{41}$ Nick Huber, 'Hitting Targets? The State of UK IT Project Management', Computer Weekly, 4 November 2003, pp. 22-4.

42 K. El Emam and A.G. Koru, 'A Replicated Survey of IT Software Project Failures', IEEE Software, vol. 25, no. 5, 2008, pp. 84-90.

43 Ted Ritter, 'Public Sector IT Projects Have Only 30\% Success Rate-CIO for Department for Work and Pensions', Computerweekly.com, 17 May 2007, <http://www.computerweekly.com/blogs/publicsector $/ 2007 / 05 /$ public-sector-it-projects-have.html>.

44 D. Cartwright 'Bank of Queensland's Eftpos Terminals Go Down Costing Retailers Thousands', News.com, 3 January 2010, <http://www.news.com.au/business/bank-of-queenslands-boq-eftposterminals-leaving-retailers-in-red/story-e6frfm1i-1225815661315>; L. Vasek, 'Passengers Suffer as Qantas Check-in Fails', Australian, 3 January 2010,

<http://www.theaustralian.com.au/news/nation/passengers-suffer-as-qantas-check-in-fails/storye6frg6nf-1225815766046>.

45 Kling, pp. $206 f f$.

${ }^{46}$ Jonathan G. Koomey, 'Worldwide Electricity used in Data Centers', Environmental Research Letters, vol. 3, no. 3, <http://iopscience.iop.org/1748-9326/3/3/034008/>.

47 Barbara Ehrenreich, Bright-Sided: How the Relentless Promotion of Positive Thinking Has Undermined America, Metropolitan Books, New York, 2009.

48 Lucy Suchman and L. Bishop, 'Problematizing "Innovation” as a Critical Project', Technology Analysis and Strategic Management, vol. 12, no. 3, pp. 327-33, p. 330.

${ }^{49}$ Lucy Suchman, 'Making Work Visible', Communications of the ACM, vol. 38, no. 9, 1995, pp. 56-64, p. 59.

50 David Graeber, Fragments of an Anarchist Anthropology, Prickly Paradigm, Chicago, 2004, pp. 71ff. 
${ }^{51}$ A.M. Hickey, A.M. Davis and D. Kaiser, 'Requirements Elicitation Techniques: Analysing the Gap Between Technology Availability and Technology Use', Comparative Technology Transfer and Society, vol. 1, no.3, pp. 279-304, p. 280.

52 J.P. Marshall and D. Zowghi, 'Software and the Social Production of Disorder' in Proceedings of the 2010 IEEE International Symposium on Technology and Society, ed. K. Michael, 2010, < http://ieeexplore.ieee.org/stamp/stamp.jsp?tp=\&arnumber=5514628>, pp. 284-91. 